num Tipo Classe I. Após a análise clínica e radiográfica da má oclusão, foi solicitada uma cintigrafia óssea por suspeita de hipercondilia unilateral direita. A distribuição assimétrica considerável do radiofármaco, confirmou a suspeita de diagnóstico. Todo o tratamento realizado seguiu um padrão pluridisciplinar, com a intervenção do ortodontista e do cirurgião maxilofacial. Foram efetuadas duas intervenções cirúrgicas em dois tempos distintos: condilectomia e cirurgia ortognática unimaxilar (mandibula). A comunicação oral que apresentamos versa sobre os fundamentos que sustentam o tratamento da hipercondilia mandibular unilateral no adulto em dois momentos cirúrgicos com benefícios visíveis na estética facial aliada à obtenção da saúde articular, muscular e dentária.

http://doi.org/10.24873/j.rpemd.2019.12.672

\section{\#SOPDF-07 Ortopedia pré-cirúrgica com molde nasoalveolar em pacientes com fenda lábio palatina}

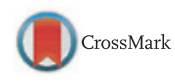

Inês Francisco ${ }^{1}$; Vanda Conceição²; Adriana Guimarães ${ }^{1}$; Anabela Pedroso ${ }^{1}$; Francisco do Vale ${ }^{1}$

${ }^{1}$ Faculdade de Medicina da Universidade de Coimbra;

${ }^{2}$ Hospital Pediátrico de Coimbra

Introdução: A fenda lábio palatina é a malformações anatómica congénita da região da cabeça mais prevalente. Durante os primeiros meses de vida do bebé a reconstrução alveolar e nasal constitui o principal desafio para o cirurgião. A intervenção precoce com o modelador nasoalveolar no recém nascido tem como objetivo modelar o maxilar, alvéolo e os tecidos nasais antes da primeira cirurgia. Este dispositivo permite o alinhamento dos segmentos alveolares, correção da asa do nariz, columela, base alar bem como o filtro labial. O objetivo deste trabalho é descrever dois casos clínicos de recém nascidos com fenda lábio palatina sujeitos a ortopedia pré-cirúrgica com o molde nasoalveolar. Descrição de caso clínico: Foram selecionados dois recém nascidos, do sexo masculino, com fenda lábio palatina esquerda do Instituto de Ortodontia da Faculdade de Medicina da Universidade de Coimbra. Ao $14^{\circ}$ dia foi realizada a impressão para o dispositivo ortopédico. Ao $18^{\circ}$ dia iniciou-se a aplicação do modelador nasoalveolar. A moldagem do nariz com a colocação do apoio nasal foi iniciada após 6 semanas de tratamento. As consultas de controlo realizaram-se semanalmente, terminando o processo imediatamente antes da cirurgia, ao fim das 12-14 semanas de vida. Discussão: A modelação dos tecidos foi medida pela aproximação dos segmentos do lábio superior, verificou-se uma redução de $3,5 \mathrm{~cm}$ para 0,9 $\mathrm{cm}$ no primeiro caso e de $3 \mathrm{~cm}$ para $1,2 \mathrm{~cm}$ no segundo caso. Conclusão: O tratamento ortopédico pré-cirúrgico em doentes com fenda lábio palatina tem como objetivo reduzir a severidade da deformidade oro nasal antes da cirurgia. O molde nasoalveolar facilita e optimiza o procedimento cirúrgico, melhorando a reorganização da cartilagem nasal, pré maxila e tecido alveolar, permitindo obter resultados mais estáveis e estéticos.

http://doi.org/10.24873/j.rpemd.2019.12.673
\#SOPDF-08 Tratamento ortopédico da classe III com recurso a ancoragem óssea: caso clínico

\author{
Gonçalo Barragan ${ }^{1}$; Johan Aerts² \\ ${ }^{1}$ Faculdade de Medicina Dentária da Universidade de Lisboa; \\ ${ }^{2}$ Vrij Universiteit van Brussels;
}

Introdução: A má oclusão de Classe III resulta de uma deficiência maxilar e/ou prognatismo mandibular, resultando num perfil côncavo e mordida cruzada anterior. Em pacientes jovens são utilizadas forças pesadas para tracção anterior da maxila, estimulando o seu crescimento e redireccionando/ restringindo o crescimento mandibular com recurso a máscara facial. No entanto, esta abordagem está associada a um aumento da dimensão vertical facial por rotação posterior da mandíbula e pro-inclinação incisiva, sendo necessária compliance por parte do paciente. Em 2009, Hugo de Clerk publicou a descrição de um caso clínico mostrando a eficácia da utilização de ancoragem esquelética como ancoragem para aplicação de forças elásticas para correcção de classe III esquelética. Lin Lu (2015) publicou um artigo demonstrando a eficácia da utilização de expansores híbridos para o tratamento de mordida cruzada posterior em adolescentes. Nesse estudo, verificou-se que os expansores híbridos, quando comparados com os dentossuportados, provocam maior expansão óssea, menos deiscências ósseas e menor tipping ao nível dos pré-molares. Em 2017, Al-Mozany publicou um artigo demonstrando a combinação de expansores híbridos e ancoragem esquelética no tratamento de pacientes de classe III em crescimento. Descrição do caso Clínico: Paciente do sexo feminino, 10 anos de idade, classe III esquelética, mordida cruzada anterior. Tratada com recurso a um expansor híbrido, uma placa mentoniana e elásticos intermaxilares. O caso foi finalizado com aparatologia fixa 022 para correcção do apinhamento dentário. Tempo de tratamento: 26 meses. Discussão: A abordagem apresentada mostrou resultados positivos no tratamento da classe III de pacientes em crescimento. Esta abordagem parece ser uma alternativa válida à abordagem clássica com máscara facial e expansor dentossuportado. A presente técnica demonstra como vantagens o conforto do paciente,a maior compliance e a redução da pro-inclinação incisiva, sendo que é também eficaz em pacientes mais velhos (10/12 anos). A principal desvantagem advém da necessidade de uma intervenção cirúrgica invasiva para a colocação da ancoragem esquelética. Conclusão: A combinação de um expansor híbrido associada com ancoragem esquelética na arcada mandibular mostra bons resultados no tratamento de classes III esqueléticas em pacientes na fase final de crescimento. http://doi.org/10.24873/j.rpemd.2019.12.674

\section{\#SOPDF-09 Como uma técnica ortodôntica pode evitar uma cirurgia ortognática \\ Fabio Parnaibaํㅜ Tassio Drieu²; Dasha Zaslonkina² \\ ${ }^{1}$ OdontoSerra; ${ }^{2}$ Clinica Odontologica}

Introdução: A maloclusão de Classe III ângulo alto é uma condição esquelética reversa e pode estar associada a mordida 
aberta. A dimensão vertical excessiva, plano oclusal reto, Curva de Spee invertida por discrepância molar inferior, ângulo FH-MP obtuso são as características morfológicas de Classe III ângulo alto. O tratamento usual para esse tipo de maloclusão é o uso de dispositivo de protração maxilar, aparelho mentual, e ou cirurgia ortognática. Paciente de 19 anos de idade masculino encaminhado ao consultório com solicitação de tratamento ortodôntico para procedimento de cirurgia ortognática. Foi decidido com o paciente realizar todo o tratamento ortodôntico com a técnica MEAW, evitando que o paciente fosse submetido a um procedimento cirúrgico ortognático. O tratamento tem até o momento a duração de 12 meses até janeiro de 2019. As análise de Slavicek, Sato e Kim (Antes / Norma / Depois) da radiografia lateral são: Plano Mandibular $35,5^{\circ}\left(21,5^{\circ}\right)$ 31,4 ${ }^{\circ}$; Facial Taper $52,7^{\circ}\left(68,0^{\circ}\right) 54,5^{\circ}$; Posição Maxilar 54,1 ${ }^{\circ}$ $\left(65,0^{\circ}\right) 48,1^{\circ}$; Convexidade -7,6 mm (-1,0mm) -8,8 mm; Eixo DOP 27,7 mm (40,9 mm) 35,7 mm; PP-PM 36,6 ${ }^{\circ}\left(24,6^{\circ}\right)$ 39, $5^{\circ}$; OP-MP $23,2^{\circ}\left(13,2^{\circ}\right) 23,7^{\circ}$; AB-MP 50,2 ${ }^{\circ}\left(71,3^{\circ}\right)$ 47, $6^{\circ}$; A'-P' 50,0 $\mathrm{mm}(27,0 \mathrm{~mm}) 25,2 \mathrm{~mm}$; A'-6' 10,6 mm (23,0 mm) 8,6 mm; ODI $45,6(72,0) 39,3$; APDI $93,1^{\circ}\left(81,0^{\circ}\right) 92,8^{\circ}$. O desenvolvimento da mordida aberta tem sido interpretado por muitos ortodontistas como uma espécie de desarmonia do desenvolvimento da mandíbula, hábitos anormais de função dos lábios e da língua e erupção dental excessiva. Enquanto outros acreditam que a deficiência da dimensão vertical posterior tem um efeito patológico, exercendo forças de abertura que não só produzem um deslizamento mesial dental, mas também uma erupção excessiva dos molares causando um aumento na dimensão oclusal vertical posterior com o achatamento subsequente do plano oclusal e uma rotação no sentido horário da mandíbula. Apesar de algumas medidas e ângulos não estarem próximos da norma, uma oclusão funcional de Classe I foi obtida com a técnica MEAW/GEAW, evitando que o paciente fosse submetido a tratamento cirúrgico invasivo e de alto custo. O paciente ficou completamente satisfeito com o resultado obtido, e o profissional foi capaz de atestar que a técnica MEAW/GEAW é completamente eficiente nos casos de tratamento com mordida aberta III.

http://doi.org/10.24873/j.rpemd.2019.12.675

\#SOPDF-10 Avaliação de dois métodos de tração de caninos inclusos - Caso clínico

Paulo Fernandes Rettoํㅜㅇ Inês Anselmo Assunção; Hélder Nunes Costa ${ }^{1}$; François Durant Pereira ${ }^{1}$; Pedro Mariano Pereira ${ }^{1}$

${ }^{1}$ Instituto Superior Egas Moniz

Introdução: Os caninos superiores permanentes apresentam, depois dos terceiros molares, a maior incidência de inclusão, especialmente na região palatina. Existem vários métodos de tração de caninos inclusos não havendo consenso sobre qual o mais eficaz. Neste poster clínico pretende-se comparar dois métodos de tração de caninos inclusos: com recurso a fios elásticos e com recurso a uma mola balista. Descrição do caso clínico: Paciente do género masculino com 16 anos de idade, apresentava uma Má Oclusão de Classe I com persistência dos caninos decíduos maxilares e inclusão palatina dos dentes 13 e 23. Ambas as inclusões apresentavam idêntica severidade, com localização transversal no sector três e distanciando do plano oclusal 14,9 mm e 15,9 mm, respetivamente no lado direito e esquerdo, apresentando bom prognóstico para tração A avaliação esquelética revelou um padrão vertical mesodivergente e uma relação basal sagital neutra. Após alinhamento e nivelamento e início da gestão do espaço, foi realizada a exposição cirúrgica dos caninos inclusos, por técnica de erupção fechada, para colagem de um botão em ambas as coroas. Simultaneamente foi realizada a extração dos dentes decíduos. A tração ortodôntica foi iniciada de imediato. Do lado direito a força foi gerada com recurso a fios elásticos contínuos e do lado esquerdo com recurso a uma mola balista. Discussão: Diversos métodos de tração estão descritos na literatura, sem que exista consenso sobre o ideal. Pretendeu-se comparar e fazer uma avaliação critica de dois métodos de tração, num paciente que apresentava dois caninos com um grau de inclusão similar. A tração com recurso a elásticos mostrou ser um método simples, em que é fácil de controlar a direção de tração, com a desvantagem de ocorrer uma decadência rápida da força devido á deterioração temporal do elástico. A mola balista apesar de ser mais complexa de elaborar, permite gerar uma força mais continua, mas em que a direção de tração é mais vertical e não tão dirigida para o espaço edêntulo. Conclusões: Ambos os métodos avaliados produziram os resultados pretendidos, apresentado uma idêntica eficácia e eficiência. O método de tração com recurso a fios elásticos requer porventura menor exigência técnica do que o do dispositivo de mola balista, uma vez que esse último deve ser construído. A decisão do método a utilizar deverá utilizar como principal critério a localização inicial do dente incluso e o local de erupção pretendido.

http://doi.org/10.24873/j.rpemd.2019.12.676

\#SOPDF-11 Auto-transplante de um pré-molar no tratamento de uma agenesia

Joana Godinhoํㅜ ${ }^{1}$ Catia Manilha ${ }^{1}$; António Ginjeira ${ }^{1}$

${ }^{1}$ Universidade de Lisboa, Faculdade de Medicina Dentária

Introdução: Em casos de agenesia, o auto-transplante pode ser uma alternativa em relação ao encerramento do espaço, ou abertura para colocar um implante. Para o sucesso deste tratamento, é fundamental o momento da realização do auto-transplante e uma técnica cirúrgica rápida, cuidada e precisa. Descrição do caso clínico: Paciente do sexo feminino, com 11.2 anos, em fase final da dentição mista. Apresentava uma Classe II esquelética e padrão hiperdivergente, com ligeira pro-inclinação dos incisivos superiores. A falta de espaço era moderada na maxila e ligeira na mandíbula, a sobremordida horizontal aumentada e a Classe II molar maior à esquerda que à direita. Na ortopantomografia, verificou-se a agenesia do dente 45. O plano de tratamento consistiu na extração do 15 e 24, com auto-transplante do 15 para o local do 45. Antes da cirurgia, foi realizada uma tomografia computorizada de feixe cónico para se criar um ficheiro .STL do dente 45 , que foi posteriormente fabricado em polimetilmetacrilato, numa fre- 